\title{
Thyroid storm during induction of anesthesia
}

\author{
Jong Taek Park, Hyun Kyo Lim, Jong Hyeon Park, and Kwang Ho Lee \\ Department of Anesthesiology and Pain Medicine, Yonsei University Wonju College of Medicine, Wonju, Korea
}

Thyroid storm is characterized by rapidly increased circulation of T3, T4, or both with worsened hyperthyroidism, hyperthermia, tachycardia, and hypertension. Although many case reports have been presented on thyroid storm, which occurs during surgery [1], case reports on thyroid storm that occurs prior to the induction of anesthesia are rare [2]. We present a case where a patient underwent a thyroid storm during anesthesia induction, even though she had neither a history of hyperthyroidism, nor abnormal findings in the preoperative evaluation.

A 50 year-old female patient (height $156 \mathrm{~cm}$, weight $59 \mathrm{~kg}$ ) was diagnosed with a humerus fracture, and was, therefore, admitted for an open reduction and internal fixation. The examination findings upon being admitted were normal. Preoperative electrocardiogram showed tachycardia with a heart rate of $90-100$ beats $/ \mathrm{min}$. Her past history showed no diagnosis of hypertension, diabetes mellitus, or thyroid disease. However, the patient had experienced $6 \mathrm{~kg}$ weight loss, intermittent palpitation, and hand tremors for the past 1 year. There were no abnormal laboratory findings. The patient had no history of past surgeries or experience with anesthesia.

Upon arriving on the operating table, her blood pressure was $125 / 85 \mathrm{mmHg}$, body temperature was $36.5^{\circ} \mathrm{C}$ and her heart rate was about $90-100$ beats/min. She did not complain of anxiety or discomfort. The patient did not receive premedication in the ward. While performing ECG and pulse oximetry monitoring, glycopyrrolate $0.2 \mathrm{mg}$ was intravenously administered before general anesthesia induction. After injection of glycopyrrolate, her blood pressure increased from $120 / 80 \mathrm{mmHg}$ to $200-$ 220/110 $\mathrm{mmHg}$, her heart rate also elevated from 100 beats/ min to $170-190$ beats/min, and a severe diaphoresis was observed. Respiration also weakened, and the patient was losing consciousness. Therefore, $100 \%$ oxygen was administered and assisted ventilation was performed, followed by an endotracheal intubation without muscle relaxants. Her body temperature increased to $39^{\circ} \mathrm{C}$. At first, we suspected malignant hyperthermia. To reduce body temperature, ice packs were applied on the neck, axillar, and groin sites, and cooled lactated Ringer's solution was infused. Esmolol and labetalol were, intravenously, administered to reduce high blood pressure. In the pulse oxymetry, oxygen saturation was maintained at $97-100 \%$. The end-tidal carbon dioxide level was maintained at around 40 mmHg. Physical examination showed no findings of muscle rigidity, including in the masseter muscle. We finally made an impression of the thyroid storm. After a 40 minute adjustment of blood pressure and heart rate, with labetalol and esmolol, the patient's consciousness returned and blood pressure was stable at $110-130 / 80-90 \mathrm{mmHg}$. The patient's body temperature stabilized at around $37.5^{\circ} \mathrm{C}$.

The surgery was postponed. A thyroid hormone test showed $\mathrm{TSH}<0.08 \mu \mathrm{IU} / \mathrm{ml}$ (normal: $0.35-5.50 \mu \mathrm{IU} / \mathrm{ml}$ ), T3 $>6.64 \mathrm{ng} /$ $\mathrm{ml}$ (normal: $0.60-1.81 \mathrm{ng} / \mathrm{ml}$ ), and free $\mathrm{T} 45.48 \mathrm{ng} / \mathrm{dl}$ (normal: $0.83-1.76 \mathrm{ng} / \mathrm{dl})$. Anti-thyroid antibodies, thyroglobulin in $\mathrm{Ab}$, were $1,116 \mathrm{IU} / \mathrm{ml}$ (normal $<115 \mathrm{IU} / \mathrm{ml}$ ). These patterns corresponded to a thyroid storm. Anti-thyroid antibodies were positive and Graves' disease was confirmed with a thyroid function test. Thus, antithyroid drug, methimazole was administered to the patient. Euthyroid state was achieved and the patient received operation for humerus fracture after 1 month later.

In the past, thyroid surgery was the most common cause of thyroid storm and when a thyroid storm occurs with surgery, it commonly occurs 6-18 hr post-surgery $[3,4]$. However,

Corresponding author: Kwang Ho Lee, M.D., Department of Anesthesiology and Pain Medicine, Yonsei University Wonju College of Medicine, 162, Ilsan-dong, Wonju 220-701, Korea. Tel: 82-33-741-1536, Fax: 82-33-742-8198, E-mail: khl6006@yahoo.co.kr

(c) This is an open-access article distributed under the terms of the Creative Commons Attribution Non-Commercial License (http:// creativecommons.org/licenses/by-nc/3.0/), which permits unrestricted non-commercial use, distribution, and reproduction in any medium, provided the original work is properly cited. 
recent preoperative medication creates a euthyroid state before performing surgery, although its occurrence is low [3]. The clinical sign of the thyroid storm, due to the abrupt release of T4 and T3 into the circulation. In this case, T3 and T4 levels abruptly increased. When surgery is performed, without the awareness of the patient having hyperthyroidism, the likelihood of a thyroid storm occurrence increases. To reduce the occurrence of thyroid storm, adequate premedication is needed, when performing anesthesia. Barbiturates or benzodiazepines should be administered to adequately sedate the patient. Anticholinergic drugs, especially atropine, are usually not administered because atropine deter the normal heat control mechanism and cause tachycardia.

In this case, the electrocardiogram from 6 months prior showed a heart rate of $70-80$ beats $/ \mathrm{min}$, and in the tests after the patient was admitted into the hospital, the blood pressure was normal, the body temperature was $36.5^{\circ} \mathrm{C}$, and the electrolytes test and blood test appeared normal. Therefore, the surgery was expected to be uneventful. However, the preoperative electrocardiogram showed tachycardia of 90-100 beats/min. Although the patient had no past history of a thyroid disease, it was confirmed that in the past 1 year, the patient had experienced a $6 \mathrm{~kg}$ weight loss, intermittent palpitation, and hand tremors. Therefore, although hyperthyroidism was not diagnosed, if there had been more appropriate history-taking, hyperthyroidism could have been suspected.
There has not been a case report of considering glycopyrrolate, as an etiologic factor of thyroid storm. Psychological stress, among many other initiating factors, is considered to have another significant role in causing the thyroid storm. Even though the patient's heart rate was 90-100 beats/min on the operating table, the administration of glycopyrrolate, without premedication in the general ward, was not appropriate because it is an anticholinergic drug, which further increases the heart rate by stimulating the sympathetic nervous system. In conclusion, if abnormal findings, such as tachycardia, weight loss, and tremors are found, or if hyperthyroidism is suspected even though a patient does not have a history of hyperthyroidism, a preoperative thyroid function test should be performed. Also, an anesthesiologist should consider potential thyroid storm, due to intravenous glycopyrrolate administration in patient with hyperthyroidism or hyperthyroidism like symptoms.

\section{References}

1. Gavin LA. Thyroid crises. Med Clin North Am 1991; 75: 179-93.

2. Hirvonen EA, Niskanen LK, Niskanen MM. Thyroid storm prior to induction of anaesthesia. Anaesthesia 2004; 59: 1020-2.

3. Kang YS, Kim JW, Hong KH. Thyroid storm during thyroidectomy of the thyrotoxicosis patient. Korean J Anesthesiol 1998; 35: 385-90.

4. Peters KR, Nance P, Wingard DW. Malignant hyperthyroidism or malignant hyperthermia? Anesth Analg 1981; 60: 613-5. 